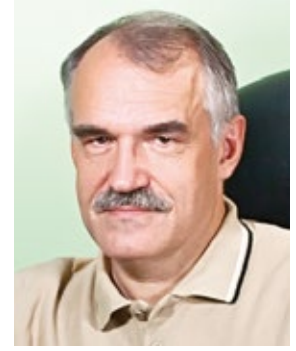

С. Н. Щербо

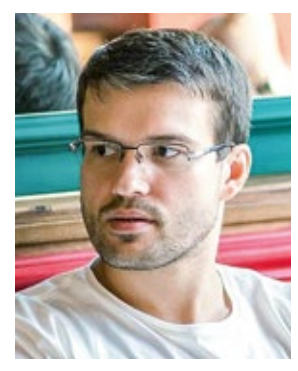

А. С. Щербо

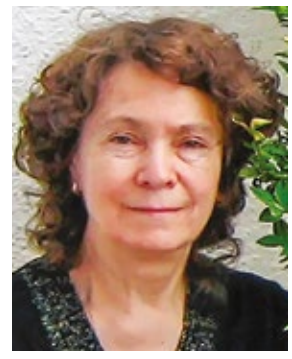

М.И. Савина

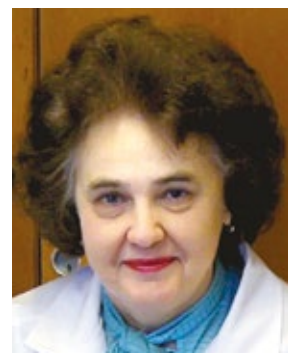

Т.И. Туркина

Генетическая предрасположенность и устойчивость к некоторым инфекционным заболеваниям. І. СПИД

\author{
С.Н. Щербо, А.б.н., профр., зав. кафелрой клинической ^абораторной
} АИагнОстикИ ФАПО

А.С. Щербо, к.б.н., Аоцент кафреАры'

А. ^. Тищенко, А.М.Н., профр., зав. кафредрой кожных и венерических болезней и косметологии ФНМО МеАицинского института ${ }^{2}$

М.И. Савина, А.б.н., профр., профр. кафредры'

Т.И. Туркина, А.б.н., профр., профр. кафредры

'KadpeАpa КАинической ^абораторной Аиагностики ФАПО ФГБОУ ВО «Российский национальный исслеАОвательский меАицинский университет имени Н.И. Пирогова» МинзАрава России, г. Москва 2ФГАОУ ВО «РОссийский университет Аружбы народов», г. Москва

\title{
Genetic predisposition and resistance to certain infectious diseases. I. AIDS
}

S. N. Shcherbo, D.S. Shcherbo, A. L. Tishchenko, M.I. Savina, T.I. Turkina

Russian National Research Medical University n.a. N.I. Pirogov, People's Friendship University of Russia; Moscow, Russia

Резюме

В обзоре рассматриваются вопросы, связанные с генетической преАрасположенностью и устойчивостью к инфекционным заболеваниям. Генетические факторы в значительной мере опреАеляют восприимчивость организма к различным заболеваниям, в том числе к инфекционным. Показана генетическая преАрасположенность к туберкулезу, сальмонемлезу, вирусным гепатитам, клещевому энцефалиту, болезни Аайма, ВИЧ и Аругим. Знание молекулярно-генетических биомаркеров необходимо А^я выАеления групп риска, провеАения преАиктивных мероприятий, в частности вакцинации. Основное вАияние УАеляется генам главного компмекса гистосовместимости, показана роль митохонАрИаАьной АНК в восприимчивости к ВИЧ-инфекции.

КАЮчевые САова: ВИЧ, СПИА, ОАнонукАеотиАные полиморфизмы, ^абораторные биомаркеры, гены главного комп^екса гистосовместимости, гап^огруппы митохонАриальной АНК.
Summary

The review addresses issues related to genetic predisposition and resistance to infectious diseases. Genetic factors largely determine the susceptibility of the body to various diseases, including infectious ones. A genetic predisposition to tuberculosis, salmonellosis, viral hepatitis, tick-borne encephalitis, Lyme disease, HIV and others is shown. Knowledge of molecular genetic biomarkers is necessary for identifying risk groups, conducting predictive measures, in particular vaccination. The main influence is given to the genes of the main histocompatibility complex; the role of mitochondrial DNA in susceptibility to HIV infection is shown.

Key words: HIV, AIDS, single nucleotide polymorphisms, laboratory biomarkers, genes of the main histocompatibility complex, haplogroups of mitochondrial DNA. $\prod^{\circ}$ очти четверть ежегодных смертельных случаев во всем мире происходят из-за инфекционных заболеваний (ИЗ) [1]. Большую роль в контроле и своевременной диагностике ИЗ сыграли и играют молекулярно-генетические методы и, в частности, разработанный в конце прошлого века метод полимеразной цепной реакции (ПЦР), который наряду с успехами в фармакологии позволил значительно снизить смертность от ИЗ. В настоящее время существует потребность в совершенствовании и разработке новых методов лабораторной диагностики, более эффективных вакцин и лучших терапевтических стратегий, в частности в связи с распространенностью антибиотикорезистентных штаммов. Успех решения указанной проблемы связан с пониманием механизмов взаимодействия «инфекционный агент организм человека» на клеточном и молекулярном уровнях, выявлении предиктивных биомаркеров предрасположенности и тяжести протекания ИЗ в различных популяциях. К ИЗ необходимо подходить как мультифакториальным (МФЗ), зависящим от индивидуальных генетических особенностей как отдельных инди- видуумов, так и популяции, с учетом различных эпигенетических воздействий. Воздействие инфекционных агентов следует рассматривать как внешнее, формирующее генетические особенности популяций. Огромное влияние на формирования предрасположенности и устойчивости к ИЗ сыграли многочисленные эпидемии. Так, эпидемия бубонной чумы, уничтожившая миллионы жителей Европы в XIV веке, в итоге положительно повлияла на здоровье и продолжительность жизни выживших поколений [2]. Такой вывод сделала антрополог, изучавшая костные 
останки жителей Лондона, живших до, во время и после «черной смерти». Во время первой волны эпидемии (1347-1351 годы), инфекция унесла жизни примерно $30 \%$ европейцев, в частности погибли около половины лондонцев, в первую очередь старики и люди всех возрастов со слабым здоровьем. Было установлено, что поколение, пережившее бубонную чуму, стало в среднем значительно здоровее, устойчивее к ИЗ, в том числе к повторным вспышкам чумы, и долговечнее: многие из выживших и их потомков доживали до 70-80 лет, чего практически не наблюдалось ранее, изменилась структура смертности. Бубонная чума оставила след в геноме переживших эпидемию поколений в пользу тех, кто нес определенные гены иммунной системы.

К категории мультифакториальных признаков, помимо прочих, относится и наследственная составляющая чувствительности к инфекциям. Генетические факторы в значительной мере определяют восприимчивость организма к различным заболеваниям, в том числе инфекционным. Генетическая предрасположенность к ИЗ может быть обусловлена целым рядом факторов [3]. Наличие в геноме человека совокупности генов, определяющих такую предрасположенность, обусловливает особенности защитного реагирования макроорганизма на инвазию патогенов. Известно, что тяжесть протекания ИЗ обусловлена сложным комплексом взаимодействия паразита и хозяина, при этом иммунный статус последнего играет столь же важную роль, что и тип возбудителя, вызвавшего заболевание. В настоящее время все большее внимание исследователей направлено на изучение генетических основ подверженности к инфекциям различной природы. Неуклонно растет число исследований генетических ассоциаций с инфекционными заболеваниями человека, включая полногеномные ассоциативные исследования GWAS. ИЗ отличаются от неинфекционных МФЗ тем, что имеют специфическую причину заболевания - инфекционный агент. Однако развитие и характер инфекционного процесса, чувствительность организма к возбудителю определяются сложным характером взаимоотношений факторов окружающей среды, патогена, наследственных факторов. Генетика предрасположенности к ИЗ определяется формулой «одна инфекция - множество генов», а у лиц с первичными иммунодефицитами возникают различные заболевания как осложнение первичного иммунодефицита «один ген - многочисленные инфекции».

Генетическая подверженность инфекционным заболеваниям может быть реализована тремя способами: редкие мутации, приводящие к дефектам определенных звеньев противоинфекционного иммунитета; варианты генов с относительно сильным эффектом в популяциях и родословных, переживших эпидемию ИЗ; сочетание у индивида «нормальных» аллелей генов, в отдельности имеющих слабый эффект, но совокупность которых приводит к образованию особенности иммунитета, предполагающих к развитию ИЗ (наиболее вероятный вариант). Показана генетическая предрасположенность к туберкулезу, сальмонеллезу, вирусным гепатитам, клещевому энцефалиту, болезни Лайма, ВИЧ и др., которые будут рассмотрены нами в дальнейших публикациях. Знание таких биомаркеров необходимо для выделения групп риска, проведения предиктивных мероприятий, в частности вакцинации.

Как отмечалось выше, среди причин первой является относительно редко встречающиеся наследственные иммунодефициты, ассоциированные, как правило, с дефектами одного гена [4]. Однако более распространенной причиной является присутствие в геноме индивидуума полиморфизмов аллелей определенных генов, каждый из которых вносит небольшой вклад в фенотип, но сочетание влияния таких аллелей дает сильный эффект и ведет к ослаблению иммунной системы. Подобные ассоциации анализируются с помощью двух подходов: во-первых, отбор генов-кандидатов по данным клиники, биохимии, а также физиологии заболевания; во-вторых, с применением технологии полно- геномного анализа скрининга ассоциаций GWAS. Первый подход не дает возможности идентифицировать новые гены в независимости от знаний их функции, и вместе с тем применительно к ИЗ - более низкая вероятность принятия ложной гипотезы, чем GWAS (при малых размерах выборок «случай - контроль» - до 250 человек) [5]. Выборка должна быть репрезентативна: для GWAS выборка больных и контроля должна быть не менее тысячи человек в каждой [6].

Технология GWAS основана на анализе большого числа полиморфизмов ДНК (секвенирование или биочипы), которые распределены по всему геному, и исследовании «распространенное заболевание распространенный вариант», в них сравнивают аллели, частота которых превышает 5 \% [7]. При поиске генетических вариантов, ответственных за тяжелые формы ИЗ, очень важен этап формирования выборок: контрольную группу целесообразно формировать из индивидуумов, у которых инфекция протекала в бессимптомной или легкой форме [8], придерживаться определенных фенотипов для предотвращения погрешностей и этнической и гендерной принадлежности (учитывать распространенность генетического фактора в данной этнической популяции).

Главный комплекс гистосовместимости (антигены лейкоцитов человека, HLA), фрагмент 4 м.п.н. на коротком плече хромосомы 6 (6p21.3) отвечает за иммунологические, аутоиммунные и инфекционные заболевания [9]. Рассмотрим применяемые для генетического анализа лабораторные технологии; так, иммуночип представляет собой платформу высокой плотности для точного и быстрого анализа ОНП в иммуногенетических исследованиях [10]. Увеличение пропускной способности, точности и длины прочитанных фрагментов характерно для технологий секвенирования следующего поколения (Next Generation Sequencing, NGS), которые вместе с развитием биоинформационных инструментов дают возможность проводить анализ главного комплекса гистосовмести- 
Таблица 1

HLA-DRB 1-маркеры чувствительности и устойчивости к различным инфекционным забомеваниям [14]

\begin{tabular}{|c|c|}
\hline Заболевание & Чувствительность \\
\hline Гепатит В & DRB $1 * 11$ (5), DR 2, DR 11 (5) \\
\hline ^епра & DR2 \\
\hline ХАамиАиоз & DRB 1*15(2) \\
\hline Папим^оматоз & DRB $1 * 16(2)$, DRB $1 * 15(2)$ \\
\hline Вирус Корсаки & DR2 \\
\hline Гистоп^азмоз & DR 15(2) \\
\hline Гепатит C & DRB $1 * 07, \mathrm{DRB} 1 * 15(2)$ \\
\hline ВИЧ-инфекция & DRB $1 * 04$, DRB $1 * 13$ \\
\hline
\end{tabular}

мости с высоким разрешением [11]. Так, полногеномный сиквенс был применен для изучения НLA-А аллелей с высоким разрешением 1070 японцев [12]. Проблемой сиквенса является относительно небольшая величина прочитываемых фрагментов, однако ПЦР РВ больших фрагментов с системой РасВіо и нанопорового секвенирования MinION позволяет эту задачу успешно решать [13]. Описан поставленный с помощью MinION рекорд по самому длинному прочтению молекулы ДНК клеточной линии человека GM12878. В итоге получили 91,2 гигабазы данных, что соответствует 30-кратному покрытию генома. Длина более половины прочтенных фрагментов ДНК составила 100 тысяч п. о. и более, и возможно определение последовательности ДНК до 882 тысяч п.о., что связано только с качеством выделения ДНК (полученная последовательность покрывает 85,8\%, а точность сборки приближается к $100 \%$ ). Известно, что локус главного комплекса гистосовместимости (HLA) имеет сложную структуру и множество повторов, поэтому его последовательность очень трудно определять. $\mathrm{C}$ технологией MinION все гены попали в одну непрерывную прочтенную последовательность, что избавило от необходимости собирать ее из фрагментов и, кроме того, распознаются эпигенетические метки (метилирование ДНК).

Благодаря чрезвычайно выраженному полиморфизму, который носит межэтнический характер, главный комплекс гистосовместимости обеспечивает выживание человека в условиях воздействия инфекционных агентов, благодаря чему совершенствуется: специфичность HLADRB $1 * 01$ ассоциирована с устойчивостью к ВИЧ-1. Генетический полиморфизм человека и устойчивость к ВИЧ / СПИД: помимо рецептора $\mathrm{CD} 4$, особое место принадлежит корецепторам, используемым ВИЧ для проникновения в клетку - наличие замены A-G в позиции 801 в 3 - нетранслируемом регионе гена $S D F 1$ при гомозиготности по аллелю SDF1-3 А достоверно ассоциировано с отсрочкой развития клинической манифестации СПИД. Хемокин SDF1, связываясь с рецептором CXCR 49 (фузин), препятствует проникновению Т-тропных штаммов вируса, характерных для поздней стадии развития инфекции - препятствие быстрой прогрессии СПИД. Частота аллеля SDF1-3 А колеблется от 3 до $43 \%$ в популяциях (в Океании $72 \%)$ и почти не встречается в Черной Африке. Основным рецептором для М-тропных изолятов ВИЧ является CCR 5, присутствие или отсутствие которого не влияет на важные процессы жизнедеятельности в организме человека. Дефектный аллель CCR 5D 32 играет значительную роль в патогенезе ВИЧ: люди с генотипом D 32/D 32 практически резистентны к вирусам генотипа R 5 и обладают частичной устойчивостью к генотипу R 5X4. В Северной Европе (Финляндия, Мордовия) частота мутации $16 \%$, на Сардинии - 4\%, и градиент расположен с севера на юг. Мутация в гене хемокинового рецептора CCR 2 приводит к замене валина на изолейцин (полиморфизм CCR 2-64I), сопровождается продлением периода сероконверсии и развитием симптомов СПИД. Защитный эффект проявляется как у гетерозигот, так и гомозигот. Протективный эффект CCR 2-64I носит опосредованный характер, так как мутация расположена в трансмембранном домене и не может влиять на эффективность проникновения ВИЧ в клетку. Аллель CCR 2-64I является наиболее распространенным в Азии и Африке - $35 \%$ и менее в Европе и Океании.

Были использованы данные о 30 тысячах ВИЧ-инфицированных европейского происхождения, из которых выделено около 500 больных с известной датой заражения и стабильными уровнями ВИЧ (вирусная нагрузка) в крови [15]. Проанализированы генетические особенности исследуемых и сопоставлены с уровнями вирусной нагрузки. В результате выяснилось, что наличие одного из вариантов гена HLA-C — rs9264942 - статистически связано со значительно меньшей скоростью размножения вируса в зараженном организме. Так, уровни вирусной нагрузки у обладаюших двумя копиями варианта rs9264942 были в среднем на $90 \%$ ниже, чем у остальных больных.

Уровень вирусной нагрузки при ВИЧ-инфекции напрямую связан с вероятностью развития СПИДа, поэтому прогноз для больных, у которых этот показатель невелик, значительно лучше, чем для тех, у кого он находится на стабильно высоком уровне.

По-видимому, мутация rs9264942 связана с повышенной выработкой HLA-C. Указанный белок играет важную роль в иммунной системе, в частности он участвует в распознавании клеток, зараженных вирусами. Ранее было установлено, что ВИЧ способен блокировать действие двух белков с аналогичными функциями под названиями HLA-A и HLA-B. Однако, судя по всему, он не способен противодействовать HLA-C. По данным генетиков, до $10 \%$ европейцев являются счастливыми обладателями двух копий rs9264942, наличие которых связано с $90 \%$-ным снижением уровня вирусной нагрузки при ВИЧ-инфекции. Еще 50 \% обладают одной копией этого гена, что 
Генетические полиморфизмы, связанные с устойчивостью и преАрасположенностью к ВИЧ-инфекции

\begin{tabular}{|c|c|c|c|c|}
\hline Тип исслеАования & Выборка & Гены & ОНП & Ссылка \\
\hline ВИЧ-1 & $\begin{array}{c}486 \text { пациентов с сероконверсией, контроль - } \\
140 \text { европейцев }\end{array}$ & $\begin{array}{l}\mathrm{HCP} 5 / \mathrm{B} * 5701 \\
\text { HLA-C }\end{array}$ & $\begin{array}{l}\text { rs2395029 } \\
\text { rs9264942 }\end{array}$ & [16] \\
\hline ВИЧ-1, контроль & 2362 европейцев & $\begin{array}{c}\text { HSPA1B-C 6orf48 } \\
\text { LOC } 105375015 \\
\text { LOC } 105375015 \\
\text { HCP5 } \\
\text { PSORS 1C 1 }\end{array}$ & $\begin{array}{l}\text { rs9368699 } \\
\text { rs9264942 } \\
\text { rs9264942 } \\
\text { s2395029 } \\
\text { rs3815087 }\end{array}$ & [17] \\
\hline Прогрессия СПИА & $\begin{array}{c}\text { Европейцы: } 275 \text { и } 86 \text { - серопозитивные без } \\
\text { прогресса и с прогрессом соответственно; } \\
1352 \text { - серонегативный контроль }\end{array}$ & $\begin{array}{c}\text { HCP5 } \\
\text { LOC } 105375015\end{array}$ & $\begin{array}{l}\text { rs2395029 } \\
\text { rs10484554 }\end{array}$ & [18] \\
\hline ВИЧ-1, контроль & $\begin{array}{c}974 \text {-контромь; } 2648 \text { инфрицированных } \\
\text { с прогрессом (европейцы, афрриканцы, } \\
\text { американцы) }\end{array}$ & $\begin{array}{c}\text { HLA-C } \\
\text { HLA-B*57:01 } \\
\text { MICA } \\
\text { PSORS 1C3 } \\
\text { HLA-B } \\
\text { Intergenic } \\
\text { HLA-B }\end{array}$ & $\begin{array}{l}\text { rs9264942 } \\
\text { rs } 2395029 \\
\text { rs } 4418214 \\
\text { rs3131018 } \\
\text { rs } 2523608 \\
\text { rs2255221 } \\
\text { rs2523590 }\end{array}$ & [19] \\
\hline ВИЧ-вОсприимчивОсть & $\begin{array}{c}6334 \text { инсицированных; } 7247 \text { - контроль } \\
\text { (европейцы) }\end{array}$ & MICA - LOC 105375017 & rs4418214 & {$[20]$} \\
\hline
\end{tabular}

связано со снижением этого показателя на $60 \%$. В то же время этот вариант гена значительно меньше распространен среди африканцев. Одна его копия встречается только у $40 \%$ выходцев с Африканского континента. Открытие нового гена может привести к разработке новых способов лечения ВИЧ-инфекции. Например, в будущем ученые смогут найти способ искусственно повысить выработку белка НLA-С в организме ВИЧ-инфицированных пациентов.

Мутация, носителями которой являются более $90 \%$ африканцев, защищает от малярии, но значительно увеличивает риск заражения ВИЧ. Данная мутация распространена исключительно среди выходцев из Африки и не встречается у представителей других этнических групп. Белок под названием DARC (Duffy-антиген рецептор для хемокинов) располагается на мембране эритроцитов. Малярийные паразиты Plasmodium vivax и Plasmodium knowlesi используют его для проникновения в красные кровяные клетки. У большинства жителей Африки белок DARC отсутствует из-за мутации соответствующего гена - это защищает их от двух типов возбудителей малярии, которые не могут размножаться в их организме. Большинство случаев малярии в Африке вызвано другим, более опасным возбудите- лем малярии Plasmodium falciparum. Несмотря на то что Африка пострадала от эпидемии ВИЧ / СПИДа значительно больше других регионов, до последнего времени не удавалось выявить специфические генетические факторы, объясняющие подверженность африканцев этой инфекции. Предполагается, что ВИЧ использует белок DARC для проникновения в эритроциты. Чтобы проверить роль белка в развитии ВИЧ-инфекции, к исследованию были привлечены 3400 чернокожих ветеранов и военнослужащих американских BBC, поскольку среди чернокожих жителей Африки было сложно найти достаточное количество людей, у которых отсутствовала мутация DARC. Как выяснилось, наличие мутации DARC было связано с $40 \%$-ным увеличением риска ВИЧ-инфекции. Генетические факторы предрасположенности к ВИЧ-инфекции, как правило, связаны с ускоренным течением заболевания. Вероятно, с мутацией гена DARC могут быть связаны как минимум $11 \%$ случаев ВИЧ-инфекции на Африканском континенте (около 2,5 млн больных). Остается неясным механизм, связывающий африканскую мутацию с повышенным риском заражения ВИЧ,- возможно, отсутствие белка DARC может приводить к снижению естественного противовирусного иммунитета.
У людей, инфицированных ВИЧ, обнаруживают антитела практически ко всем белкам вируса: и структурным, и регуляторным. До 90 \% всех обнаруживаемых у ВИЧ-инфицированного человека антител направлены как раз на один из участков, называемый доменом V3, у которого есть консервативная последовательность, к которой и образуются антитела, обладающие широким нейтрализующим действием. В организме человека ВИЧ не только не нейтрализуется антителами, но еще и распространяется по клеткам иммунной системы - макрофагам. Основную роль в реализации этого феномена (in vivo) как раз и играют антитела к домену V3. Кроме того что ВИЧ сам подвержен мутациям, его еще «принуждает» меняться иммунная система человека. Низкие концентрации вируснейтрализующих антител усиливают инфекционность вируса благодаря феномену антителозависимого усиления инфекции. Но как только их уровень достигает определенного порога, под давлением этих же антител селекционируется вариант вируса, способный избегать их нейтрализующего действия. Цикл многократно повторяется на протяжении жизни ВИЧ-инфицированного и больного СПИДом. Цель процесса - накопление более опасного варианта ВИЧ - Х4. Он очень активно 
осваивает клетки иммунной системы. Процесс накопления вариантов вируca X4 достигает максимума к концу ассимптоматического периода болезни. Когда болезнь вступает в стадию СПИДа, то и разнообразие вариантов вируса идет на убыль.

Некоторые варианты митохондриальной ДНК (гаплогруппы) ассоциируются с ускорением развития СПИДа в два раза [21]. Изучили данные пяти долгосрочных исследований с участием 1833 ВИЧ-инфицированных пациентов. Все исследования были проведены в 80-х и начале 90-х годов прошлого века, до широкого внедрения антиретровирусной терапии, что позволило проследить естественный ход развития заболевания. Определяли продолжительность течения ВИЧ-инфекции у пациентов до развития СПИД-ассоциированных заболеваний. Выяснилось, что у людей, принадлежащих к митохондриальным гаплогруппам U5a1 и J, ВИЧ-инфекция прогрессировала в два раза быстрее, чем в среднем у участников. В то же время у тех, кто принадлежал к гаплогруппе Н3, СПИД развивался более чем в два раза дольше, как показало исследование. Митохондриальные гаплогруппы различаются по количеству вырабатываемой ими энергии, причем гаплогруппы U5a1 и J вырабатывают меньшее ее количество. Провоцируемый ВИЧ апоптоз (клеточная гибель) активнее протекает в тех иммунных клетках, митохондрии которых вырабатывают меньше энергии. Этот факт может служить возможным объяснением ускоренного развития СПИДа у пациентов, принадлежащих к гаплогруппам U5a1 и J. В будущем определение митохондриальной ДНК может быть использовано при прогнозировании развития ВИЧ у пациента, а также для определения сроков начала антиретровирусной терапии.

Оказалось, что более высокий уровень выживаемости имеют носители определенного варианта ДНК митохондрий (мтДНК). Исследована структура мтДНК у 150 пациентов, госпитализированных в отделения интенсивной терапии. Ранее высказывались предположения о возможной взаимосвязи работы митохон- дрий со способностью организма противостоять тяжелым инфекциям, в частности пневмонии и MRSA (стафилококкам, обладающим устойчивостью к антибиотикам). Удалось выделить 10 основных вариантов мтДНК [22], а выживаемость пациентов оценивалась через полгода после развития тяжелых инфекций. У больных, имеющих разновидность мтДНК под названием гаплогруппа $\mathrm{H}$, показатели выживаемости оказались более чем в два раза выше по сравнению с другими девятью группами. Гаплогруппа Н - это самый молодой и одновременно самый распространенный вариант мтДНК, который имеется у $40 \%$ людей. Последнее открытие поможет разработать новые, более эффективные методы лечения, позволит использовать дифференцированный терапевтический подход к больным, имеющим разные варианты мтДНК, (имеющим меньшие шансы на выживание - более агрессивная тактика). Для этого предстоит разработать дешевые и удобные тесты определения мтДНК.

\section{Список Аитературы}

1. Morens D. M., Folkers G. K., Fauci A. S. The challenge of emerging and re-emerging infectious diseases. // Nature. - 2004. - 430.— 6996.P. 242-249.

2. DeWitte S. N. Mortality risk and survival in the aftermath of the medieval Black Death. // PLoSOne.-2014.-9.-5: e96513.

3. Kumar V., Wijmenga C., Xavier R. J. Genetics of immune-mediated disorders: from genome-wide association to molecular mechanism. // Curr. Opin. Immunol._-2014._-31.P. 51-57.

4. Boisson-Dupuis S., Bustamante J., El-Baghdadi J. et al. Inherited and acquired immunodeficiencies underlying tuberculosis in childhood. // Immunol. Rev. - 2015.264.-P. 103-120.

5. Amos W., Driscoll E., Hoffman J. I. Candidate genes versus genome-wide associations: which are better for detecting genetic susceptibility to infectious disease? // Proc. Biol. Sci.-2011.-278.-P. 1031-1037.

6. Burton P.R., Hansell A. L., Fortier I. et al. Size matters: just how big is BIG?: Quantifying realistic sample size requirements for human genome epidemiology. // Int. J. Epidemiol.2009.-38. - P. 263-273.

7. Newport M. J., Finan C. Genome-wide association studies and susceptibility to infectious diseases. // Brief Funct Genomics. - 2011.10.- P. 98-107.

8. Loeb M., Eskandarian S., Ropp M. et al. Genetic variants and susceptibility to neurological complications following West Nile virus infection. // J. Infect. Dis. - 2011. - 204.P. 1031-1037.
9. Matzaraki V., Kumar V., Wijmenga C. The MHC locus and genetic susceptibility to autoimmune and infectious diseases. // Genome Biol.-2017. - 18: 76.

10. Cortes A, Brown MA. Promise and pitfalls of the Immunochip. // Arthritis Res Ther. 2011; 13: 101. DOI: 10.1186/ar3204.

11. Carapito R, Radosavljevic M, Bahram S. Next-generation sequencing of the HLA locus: methods and impacts on HLA typing, population genetics and disease association studies. // Hum. Immunol._2016. - 77. - 11.— P. 1016-1023.

12. Nagasaki M., Yasuda J., Katsuoka F. et al. Rare variant discovery by deep whole-genome sequencing of 1,070 Japanese individvals. // Nat Commun.-2015; 6: 8018. DOI: 10.1038/ncomms9018.

13. Jain M., Koren S., Miga K.H. et al. Nanopore sequencing and assembly of a human genome with ultra-long reads. // Nat. Biotechnol.2018.-36.-4.-P. 338-345.

14. Хаитов Р. М., Алексеев А.П., Трофиимов А. Ю. Иммуногеномика и генодиагностика человека. Национальное руководство. ГЭОТАР-МеАиа.-М.-2017-256 с.

15. Fellay J., Shianna K. V., Ge D. et al. A Whole-Genome Association Study of Major Determinants for Host Control of HIV-1. // SCience.-2007.-10.1126/science.1143767.

16. Fellay J., Shianna K. V., Ge D. et al. A whole-genome association study of major determinants for host control of HIV-1. // Science.-2007. 317. P. 944-947.

17. Fellay J., Ge D., Shianna K.V., Colombo S. et al. Common genetic variation and the control of HIV-1 in humans. // PLOS Genet.-2009. - 5. DOI: 10.1371/journal.pgen.1000791.

18. Limou S., Le Clerc S., Coulonges C.et al. Genomewide association study of an AIDS-nonprogression cohort emphasizes the role played by HLA genes (ANRS Genomewide Association Study 02) // J. Infect. Dis. - 2009._199.— P. 419-26.

19. International HIV Controllers Study. Pereyra F., Jia X., McLaren P.J. et al. The major genetic determinants of HIV-1 control affect HLA class I peptide presentation. // Science.2011.-330.- P. 1551-1557.

20. McLaren P.J., Coulonges C., Ripke S. et al. Association study of common genetic variants and HIV- 1 acquisition in 6,300 infected cases and 7,200 controls. // PLoS Pathog._- 2013.9. - 7. doi: 10.1371/journal.ppat. 1003515.

21. Hendrickson S. L., Hendrickson S. L., Ruiz-Pesini E. et al. Mitochondrial DNA haplogroups influence AIDS progression // AIDS.—2008.—22.18. - P. 2429-2439.

22. Chinnery P.F., Elliott H.R., Syed A. Mitochondrial DNA haplogroups and risk of transient ischaemic attack and ischaemic stroke: a genetic association study. // Lancet Neurol. 2010.-9.-5.- C. 498-503.

А^я цитирования. Щербо С.Н., Щербо А.С., Тищенко А.А., Савина М.И., Туркина Т.И. Генетическая прелрасположенность иустойчивость к некоторым инорекционным заболеваниям. І. СПИА // МеАицинский алфравит. Серия «Современная ^абораториял - 2019.- Т. 3-22(397).- С. 6-10. 